\title{
Current Research Trends on Executive Function in Children
}

Jumi Lee

Department of Education, Chonnam National University, Gwang-Ju, Korea

\author{
국내 아동 실행기능 연구의 최근 동향 \\ 이주미 \\ 전남대학교 교육학과
}

Objective: The purpose of this study was to explore research trends in childhood executive function in Korean academic journal articles. This study showed which population groups were studied, which factors of executive function were measured, and which domains were studied in the selected articels.

Methods: A systematic review of empirical studies of childhood executive function published in Korean academic journals from 2006 to 2016 was conducted. Through searching the KERIS database, 60 empirical studies were selected for review.

Results: The results of the analyses showed that the population group the most studied was normal young children and that factors of executive function most studied were inhibition, cognitive flexibility, and working memory.

Conclusion: Based on this systematic review of empirical studies of childhood executive function, several suggestions for future research are addressed.

Keywords: executive function, children, research trends

\section{서론}

인간의 복잡한 인지 및 사고과정의 중추적 역할을 하는 실행 기능에 대한 학문적 관심은 뇌 심리학과 신경 심리학 분야 등 임상 분야에서부터 인간의 발달, 학습, 행동, 사회적 기능 등 과 관련된 다양한 분야까지 확장되어 활발히 연구가 이루어 지고 있다(Clark, Pritchard, \& Woodward, 2010; Richland \& Burchinal, 2013). 실행기능(Executive Function [EF])이란 인간 의 목표 지향적 사고, 행동, 정서를 통제하는 의식적 인지과 정이고(Zelazo \& Carlson, 2012), 일상생활과 학습상황에서 이 루어지는 다양한 문제해결 및 적응적 행동을 수행하기 위해 필수적인 복잡한 사고과정으로 정의된다(Jurado \& Rosselli,

Corresponding Author: Jumi Lee, Department of Education, Chonnam National University, 77, Yongbong-ro, Buk-gu, Gwang-ju, Korea E-mail: jlee@jnu.ac.kr
2007).

실행기능을 하나의 단일체로 보는 입장과(Duncan, Johnson, Swales, \& Freer, 1997) 다차원적 구성체로 보는 입장(Anderson \& Reidy, 2012)이 공존하며 여전히 논쟁이 되고 있다. 실행기 능의 단일성을 지지하는 입장은 실행기능이 일반적 지능이나 작업 기억과 하나의 통합기제라고 주장한다(Jurado \& Rosselli, 2007). 하지만, 이러한 단일성 주장은 전두엽 손상 환자나 Attention Deficit Hyperactivity Disorder [ADHD] 아동 등 다른 정신병리 유형에 따라 실행기능 하위 구성 요소별 수행점수가 다르다는 점을 설명하지 못한다(M. J. Lee \& Hong, 2006). 반 면에, 최근에는 실행기능이 복잡하고 고차원적인 인지과정으 로 목표 설정, 목표 달성을 위한 계획 작성, 계획의 효율적 수

(C)The Korean Association of Child Studies

This is an Open Access article distributed under the terms of the Creative Commons Attribution Non-Commercial License (http:// creativecommons.org/licenses/by-nc/4.0) which permits unrestricted noncommercial use, distribution, and reproduction in any medium, provided the original work is properly cited. 
행 등의 고차원적 인지기술들로 이루어진 구성개념이라는 주 장이 학문적 지지를 더 받고 있다(Anderson \& Reidy, 2012). 예 를 들어, 억제(inhibition), 전환능력(shifting), 최신화(updating) 가 요인분석을 통해서 실행기능을 설명하는 구성요소로 제 시되었고(Miyake et al., 2000), 억제, 인지적 유연성(cognitive flexibility), 작업 기억(working memory; Diamond, 2006, 2013; M. J. Lee \& Hong, 2006), 또는 인지적 유연성, 목표설정(goal setting), 집중적 통제(attentional control), 정보처리(information processing; Anderson \& Reidy, 2012)를 실행기능의 구성요소로 제시하는 등 많은 요소들이 실행기능을 설명하는 구성요인으 로 언급되고 연구되어 왔다.

위에 언급된 요소 중에서, 억제, 인지적 유연성, 작업 기억 은 실행기능의 구성요소로서 지속적으로 제시되었다. 억제는 자동적이고 우세하게 행해지는 행동, 생각, 반응을 고의적으 로 통제하는 능력을 말한다(Miyake et al., 2000). 전환능력이라 고도 명명되는 인지적 유연성은 과제 수행 시 쉽게 주의를 전 환하는 능력, 과제와 목표 사이를 능숙하게 옮겨 다닐 수 있는 능력, 다양한 자료를 동시에 처리할 수 있는 능력 등으로 설명 될 수 있다(Baggetta \& Alexander, 2016). 작업 기억은 관련 정보 가 빠르게 추가되고 제거되는 동안에도 과제나 아이디어를 지 속시키는 능력이다. 가장 많이 언급되는 억제, 인지적 유연성, 작업 기억 외에도 목표설정(목표 설정 및 달성을 위해 행동을 계획하고 전략적으로 이에 필요한 행동과 단계를 개발하고 조 직하는 능력; Anderson \& Reidy, 2012)이나 정보처리(새로운 문재해결을 위한 정보처리 속도, 유창성, 효율성을 포함하는 개념; Anderson \& Reidy, 2012) 등의 요소도 실행기능을 설명 하는 구성요소 또는 하위영역으로 간헐적으로 언급되고 있다. 위에서 제시된 요소들은 연구자에 따라 사용하는 용어에 차이 가 있지만, 유사한 개념 또는 영역을 명명하고 설명하는 개념 들의 많은 부분이 중복되는 경우가 많다. 예를 들어, Anderson 과 Reidy (2012)는 인지적 유연성을 집중의 분할, 작업 기억, 개 념적 전환 등의 능력을 모두 포함하는 구성개념으로 설명한 반면 Diamond $(2006,2013)$ 는 인지적 유연성과 작업 기억을 구분하여 설명하였다. 한편, Miyake 등(2000)이 제시한 최신 화는 작업 기억과 같은 개념으로 사용되고 있다(Brydges, Reid, Fox, \& Anderson, 2012). 이처럼 연구자에 따라 비슷한 실행기 능의 구성요소를 다른 용어로 명명하고 정의하는 것은 실행기 능 개념화의 불명확성을 초래하여 실행기능을 효과적으로 정 의하고 이해하는 것에 걸림돌이 될 수 있으므로 용어나 개념 에 대한 명확한 설명과 적용이 수반되어야 할 것이다(Baggetta \& Alexander, 2016).

\section{왜 아동의 실행기능 이해가 중요한가?}

인간의 지각, 사고, 행동을 조절하는 뇌의 전두엽의 발달과 실행기능의 발달이 밀접한 관계가 있다(Anderson \& Reidy, 2012). 실행기능의 발달은 아동의 발달 단계에 따라 차이를 보인다. 예를 들어, 영아는 현재 환경 안에서 주어지는 자극 에 반응하는 정도에 머물지만, 유아는 현재 환경 안에서 과거 를 생각하고 미래를 계획하는 능력과 문제를 다각도로 이해하 고 최고의 대안을 찾아내는 능력을 가지기 시작한다(Jurado \& Roselli, 2007). 이러한 예를 통해 실행기능이 아동기 동안 연속 적으로 발달하고, 이는 성장 급등(growth spurt) 시기의 전두엽 발달과 밀접한 관련이 있다고 볼 수 있을 것이다. 성장 급등 시 기는 출생에서 만 2세까지, 7세에서 9세까지, 16세에서 19세 까지를 일컫고, 이 시기 동안 전두엽이 발달하고 그 발달은 성 인초기까지 이어진다고 볼 수 있다(Jurado \& Roselli, 2007).

아동기에 실행기능이 급격하게 발달하고 사고, 정서 및 신 체 발달과 함께 학습이 활발하게 이루어지는 시기이므로 아 동의 실행기능에 대한 연구는 실행기능 장애로 초래될 수 있 는 학습적, 정서적, 행동적 문제들을 최소화하고(Anderson \& Reidy, 2012), 실행기능 발달단계에 맞는 학습 및 중재 프로그 램 개발 및 적용을 위해 필요할 것이다. 예를 들어, 실행기능이 읽기, 수학, 과학 관련 학업수행 및 성취도(Agostino, Johnson, \& Pascual-Leone, 2010; Y. S. Kim \& Kwak, 2014; Maeng, Jeong, \& Kwon, 2014; Rhodes et al., 2014) 및 학습 및 학교생활 관련 자기조절(self-regulation)과 높은 관련성이 있다는 국내외의 연 구결과(E. Choi \& Song, 2013; Kaplan \& Berman, 2010; Rueda, Posner, \& Rothbart, 2005; M.-R. Song \& Ha, 2014)는 인간의 학 습 및 행동을 이해하고 이에 영향을 주는 실행기능의 역할을 이해하는 것이 중요함을 시사한다. 또한, 성공적 학습 및 행 동수행과 자기조절의 밀접한 관련성은 여러 연구를 통해 꾸 준히 입증되어 왔고(Blair \& Diamond, 2008; Nota, Soresi, \& Zimmerman, 2004), 실행기능과 자기조절 간 유의미한 관련 성도 존재하기 때문에(Dilworth-Bart, 2012), 아동의 실행기능 에 대한 발달 및 교육심리학계의 관심은 지극히 당연한 것이 라고 할 수 있을 것이다. 이러한 이유로 아동 실행기능에 대한 연구는 지속되어야 하고, 본 연구는 국내 아동 실행기능 연구 의 2006년부터 2016년까지 최근 10년간 연구 동향 분석을 통 해 아동의 실행기능 연구가 어떻게 이루지고 있는지 이해하 여 앞으로 새로운 연구의 방향을 제시할 수 있는 기초자료로 사용되기를 기대한다. Kong과 $\operatorname{Lim}$ (2011)이 실행기능 연구 동 향 분석 연구논문을 출판한 후 아동 실행기능 관련 연구가 40 
편 이상 출판되었지만, 이 연구들에 대한 동향 분석이 실행되 지 않았고 아동 실행기능 연구에 대한 동향분석은 실행된 적 이 없기 때문에 본 연구에서 아동 실행기능 연구 동향 분석을 실행하는 것이 시기적절하다고 생각한다. 이를 위한 연구문제 는 다음과 같다.

\section{연구문제 1}

국내 아동 실행기능 연구 대상의 연령분포 및 구성은 어떠한가?

\section{연구문제 2}

국내 아동 실행기능 연구에서 연구한 실행기능의 구성요소는 무엇인가?

\section{연구문제 3}

국내 아동 실행기능 연구에서 사용한 측정도구는 무엇인가?

\section{연구문제 4}

국내 아동 실행기능 연구의 내용 동향은 어떠한가?

\section{연구방법}

본 연구를 실행하기 위하여 한국교육학술정보원(Korea Education and Research Information Service [KERIS])에서 제 공하는 연구정보 서비스(RISS)의 데이터베이스(www.riss.kr/ index.do)에서 문헌검색을 실시하였다. 문헌검색을 위해 사 용된 단어는 '실행기능', '아동 실행기능' '유아 실행기능'이 다. 최근 10 년간 국내 아동 실행기능 연구의 동향분석을 위해 2006년부터 2016년 9월까지 출판된 논문으로 제한하여 문헌 검색하였다. 또한, 보다 완성도 높은 논문만을 대상으로 하기 위해서 분석 대상 논문은 한국 연구 재단에 등재된 또는 등재 후보로 있는 학술지에 게재된 논문만을 포함하고 아동 실행기 능을 주제로 하는 석사 및 박사논문은 제외시켰다. 그리하여 총 72편의 논문 중에서 동향분석 논문을 포함한 문헌연구 논 문(e.g., Kong \& Lim, 2011; C.-W. Song \& Byun, 2007)과 한국 연구재단의 등재지 또는 등재후보지가 아닌 학술지에 게재된 논문 등 12 편을 제외하고 60 편의 논문만을 대상으로 분석을 실시하였다.

수집된 논문들은 연구문제에 따라 백분율(\%)과 빈도 $(f)$ 가 계산되었고, 논문의 내용이 분석되었다. 본 연구자가 논문의 빈도 및 내용 분석을 실시한 후 사회과학계열 박사과정 학생
이 분석결과를 점검하였다.

\section{연구결과}

\section{아동 실행기능 연구의 대상자 연령 및 구성}

국내 아동 실행기능 연구의 연구대상자의 연령과 특성별로 연 구를 분류하고 분석하였다. 연구대상자의 연령은 크게 전 학 령기 아동과 학령기 아동으로 분류한 후, 연구 대상자의 특성 에 따라 세부적으로 다시 분류하였다. 연구 대상자의 연령과 구성을 분석한 결과, 2-7세 연령의 전 학령기 일반 아동(46\%) 을 대상으로 한 연구가 가장 많았으며, 8-13세 연령의 학령 기 아동을 대상으로 한 연구 중에서 일반아동을 대상으로 한 연구(13\%)와 일반 아동과 비일반 아동을 대상으로 한 연구 (16.3\%)가 비슷한 비율로 실시되었다. 전 학령기 아동과 학령 기 아동을 모두 포함한 연구는 전체 연구의 약 $9.8 \%$ 에 해당되 었다.

연구대상자의 특성별로 살펴보면, 비일반 아동 중 $\mathrm{ADHD}$ 아동이 연구대상자로 큰 비율을 차지하는 것을 알 수 있다. $\mathrm{ADHD}$ 아동이 포함된 연구는 전체 논문의 약 $29.7 \%$ 정도를 차지했다. $\mathrm{ADHD}$ 아동과 일반 아동 간의 실행기능 비교(J. Y. Kim \& Baek, 2007; Seo \& Park, 2011), ADHD 아동, 일반 아 동, 아스퍼거 장애 아동 간의 실행기능 비교(Cho \& Lee, 2013), $\mathrm{ADHD}$ 아동, 일반 아동, 불안장애 아동 간 실행기능 비교(S. M. Park \& Shin, 2010) 등 ADHD 아동이 다양한 특성의 연 구대상자와 비교되는 연구가 높은 비율(28\%)을 차지하였다 (Table 1 참조).

또한 학습장애 아동이 연구대상으로 포함된 연구가 본 연 구에서 분석한 전체 논문의 약 $6.4 \%$ 정도를 차지하고, 이것 은 비일반 아동 대상 연구 중에서 $\mathrm{ADHD}$ 아동 다음으로 높 은 비율로 연구된 것이다. 학습부진아의 실행기능 향상에 놀 이치료 프로그램이 미치는 영향(Y. H. Kim \& Park, 2010), 학 습장애아와 일반아동의 실행기능 특성 비교(C.-W. Song, Kim, \& Chang, 2008), 읽기장애아동 간의 실행기능 특성 비교(G.Y. Jung, Kim, \& Rhee, 2014) 등 학습장애아의 실행기능에 대 한 연구가 많이 실행되었다. $\mathrm{ADHD}$ 아동이나 학습장애 아동 은 임상적 문제와 함께 사회생활과 학교생활 및 학습에서도 큰 문제가 되고 있기 때문에 이러한 아동들의 실행기능에 대 한 연구가 계속 이루어지고 있다는 것은 매우 긍정적으로 해 석된다. 또한, 다문화 배경의 아동의 실행기능 연구(C.-Y. Kim 
Table 1

Studies by Population Group

\begin{tabular}{|c|c|c|}
\hline Population group & $f$ & $\%$ \\
\hline \multicolumn{3}{|l|}{ Young children ( $2-7$ years) } \\
\hline Normal children & 27 & 46 \\
\hline Normal + ADHD & 2 & 3.4 \\
\hline Normal + Autism & 1 & 1.6 \\
\hline Normal + Gifted & 1 & 1.6 \\
\hline \multicolumn{3}{|l|}{ Children (8-13 years) } \\
\hline Normal children & 8 & 13 \\
\hline Normal + gifted & 1 & 1.6 \\
\hline Normal + ADHD & 4 & 6.7 \\
\hline Normal + ADHD + Depress & 1 & 1.6 \\
\hline Normal + ADHD + AS & 1 & 1.6 \\
\hline Normal + ADHD + LD & 1 & 1.6 \\
\hline Normal + ADHD + AS + LD & 1 & 1.6 \\
\hline Normal + LD & 1 & 1.6 \\
\hline Reading disorder & 1 & 1.6 \\
\hline ADHD & 4 & 6.7 \\
\hline \multicolumn{3}{|l|}{ Young children + Children } \\
\hline Normal + ADHD + Anxiety & 1 & 1.6 \\
\hline ADHD & 3 & 5 \\
\hline Normal + AS & 1 & 1.6 \\
\hline Autism & 1 & 1.6 \\
\hline Total & 60 & 100 \\
\hline
\end{tabular}

Note. LD = learning disability; AS = Asperger's disorder.

$\& \operatorname{Lim}, 2013)$ 나 영재아동의 실행기능 연구(H. J. Kim \& Hong, 2011b)는 최근 우리 사회나 교육현장에서 중요한 문제로 부각 되고 있는 아동을 연구대상으로 삼았다. 이들을 대상으로 연 구한 것은 주목할 만하지만, 각 1 편씩만 출판된 것이 아쉽다. 일반 아동의 학습, 생활, 행동에 관련된 실행기능 연구도 분명 히 필요하지만, 교실 내 소수집단 학습자(다문화 배경 학습자, 학습부진 학습자, 영재교육 대상 학습자 등)의 실행기능에 대 한 연구는 그들의 학습권을 보호하고 그들을 포용할 수 있는 교실문화 조성을 위해서라도 더 많은 학문적 관심이 필요할 것이다.

\section{실행기능 구성요소}

국내·외 실행기능 연구에서 다양한 요소를 실행기능의 구성요 소 또는 하위영역으로서 소개하고 연구하였다. 예를 들어, 억 제, 인지적 유연성, 작업 기억은 실행기능의 구성요소로서 지
속적으로 연구되었고(e.g., Diamond, 2006, 2013; J. M. Kim \& Kim, 2013; Y. S. Kim \& Kwak, 2014), 목표설정이나 정보처리 도 자주 언급되는 실행기능의 구성요소이다(e.g., Anderson \& Reidy, 2012; M.-R. Song \& Ha, 2014). 그러므로 본 연구에서 분석된 논문에서 사용한 구성요소들을 억제, 인지적 유연성, 작업 기억, 목표설정, 정보처리 등으로 분류하였다.

본 연구에서 분석된 국내 아동 실행기능 연구논문에서 가 장 많이 언급된 실행기능 구성요소는 억제이다. 억제, 억제적 통제, 반응억제, 또는 주의통제로 언급된 요소들이 억제로 분 류되었고, 본 연구에서 분석된 논문 60 편 중 44 편(72\%)의 논 문이 억제를 실행기능의 주요한 구성요소로서 설명하고 측 정하였다. 두 번째로 많이 설명된 구성요소는 인지적 유연성 또는 전환능력(이하 '인지적 유연성'으로 통칭함)으로 33편 (54\%)의 논문이 언급하였다. 29 편(47\%)의 논문이 작업기억 을 실행기능의 구성요소로서 연구하였다. 목표설정, 조직화, 또는 계획화(이하 '목표설정’으로 통칭함)가 총 14 편(23\%)의 논문에서 연구되었다. 그 외에 실행기능의 구성요소로서 정 보처리를 포함한 연구는 2편(3\%)이고, 정서적 실행기능 또는 인지적 실행기능을 연구한 연구는 7편(11\%)이었다. 최근 국 제 실행기능 연구 동향을 살펴보면, 억제, 작업 기억, 인지적 유연성의 순서로 자주 언급되는 것으로 나타난다(Baggetta \& Alexander, 2016). 위에서 제시한 국내 연구 동향 분석 결과가 이러한 국제적 추세와 유사함을 알 수 있다. 억제능력을 측정 한 연구 논문 44편에 대한 구체적 내용분석을 Table 2에 정리 하였다. 또한 2006년에서 2016년 사이에 국내 아동 실행기능 연구가 출판된 저널별로 분류하여 Table 3 에 정리하였다.

\section{실행기능 측정도구}

위에서 언급된 구성요소들을 중심으로 국내 아동 실행기능 연 구에서 사용된 측정도구를 살펴보았다. 각 구성요소를 측정 하기 위해 사용된 측정도구를 분류하고 비율을 분석하였다 (Table 4 참조).

실행기능의 구성요소로서 가장 많이 언급된 억제능력을 측 정하는 도구 중에서 가장 많이 사용된 것은 스트룹(Stroop) 검 사이다(13편, $11 \%)$. 스트롭 검사는 주어진 복잡한 자극들 중 한 자극에만 주의를 집중하도록 요구하는 과제이다. 예를 들 어, 여러 가지 색으로 구성된 그림에서 한 가지 색깔만 말하도 록 요구하거나(색깔과제) 여러 가지 색으로 이루어진 글자에 서 색깔에 상관없이 글자만을 읽도록 요구하는(글자과제) 등 의 과제로 방해자극을 억제하는 능력을 측정하는 도구이다(S. 

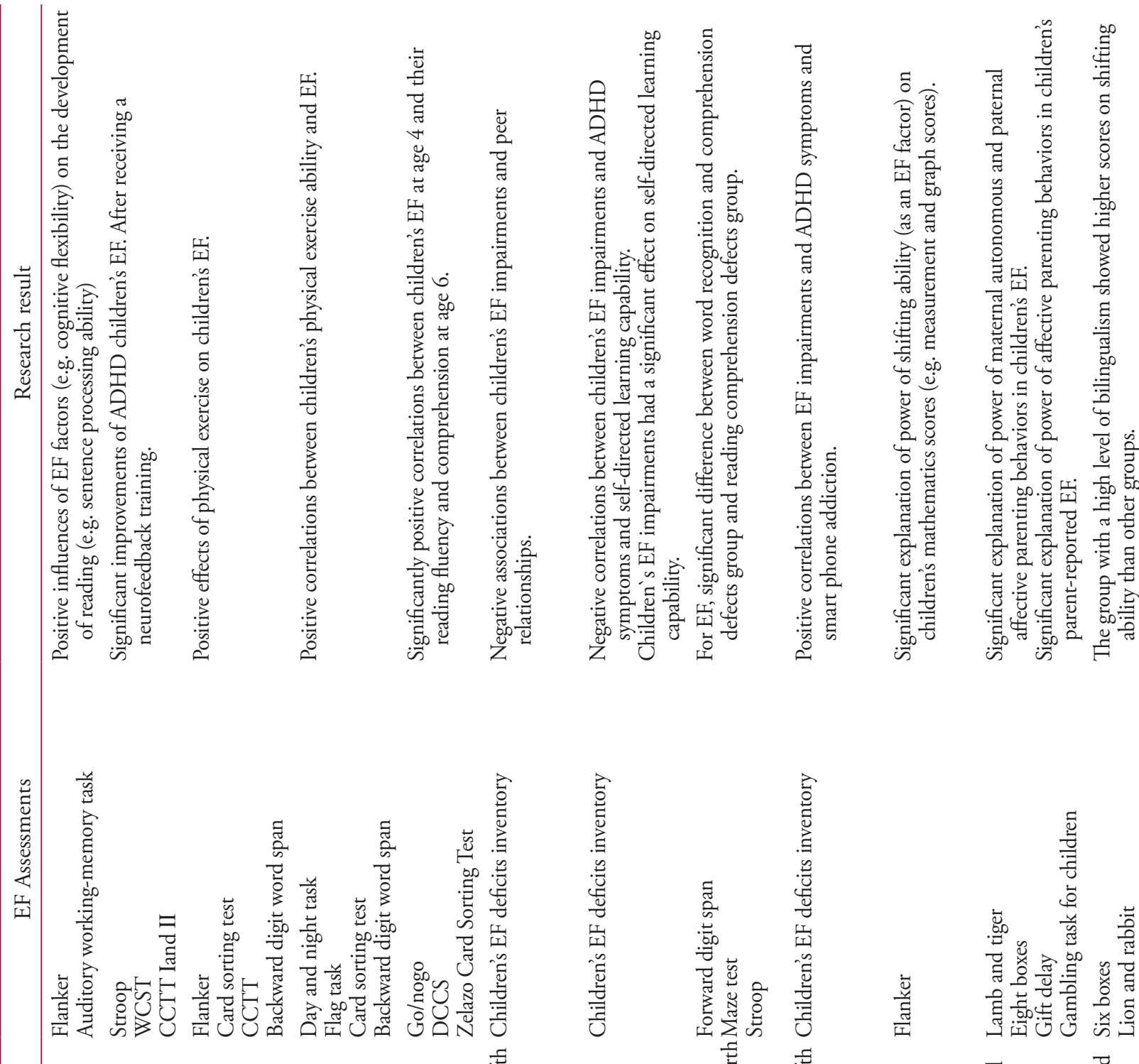

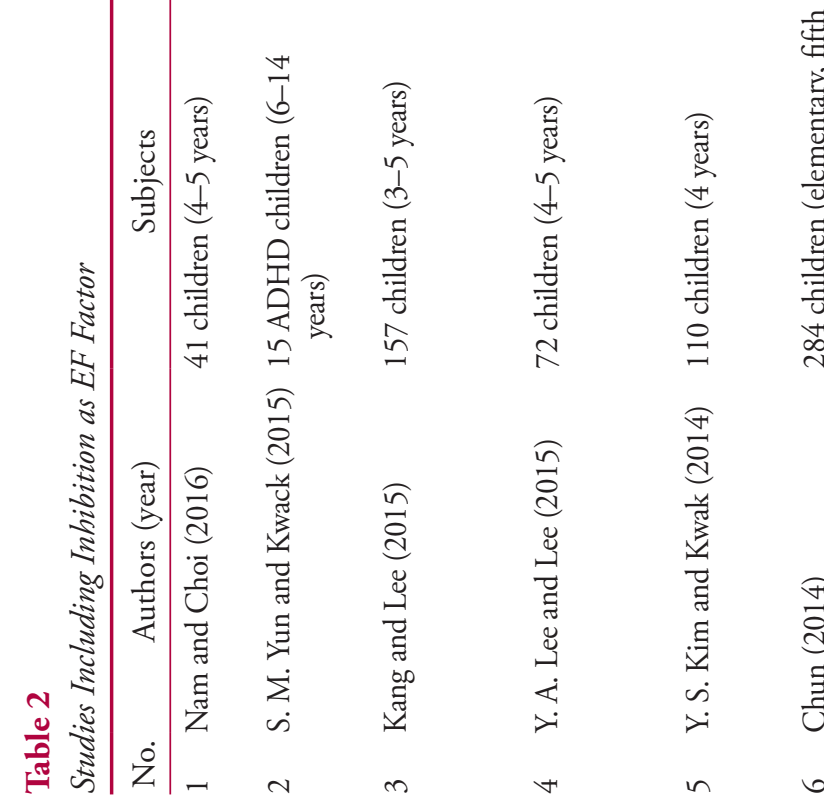

考定 吾

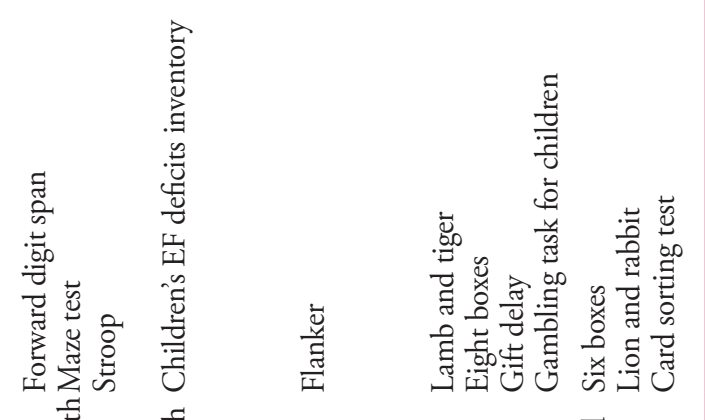

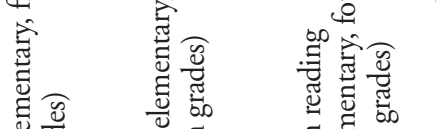

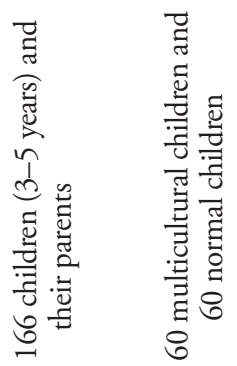

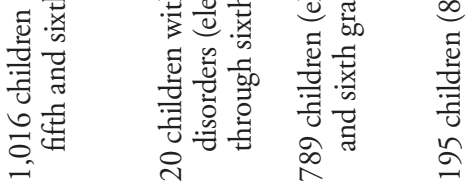

总

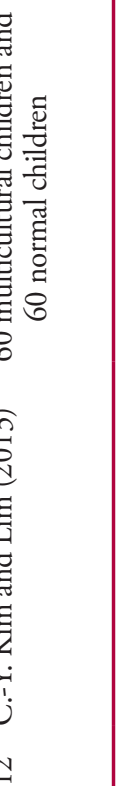




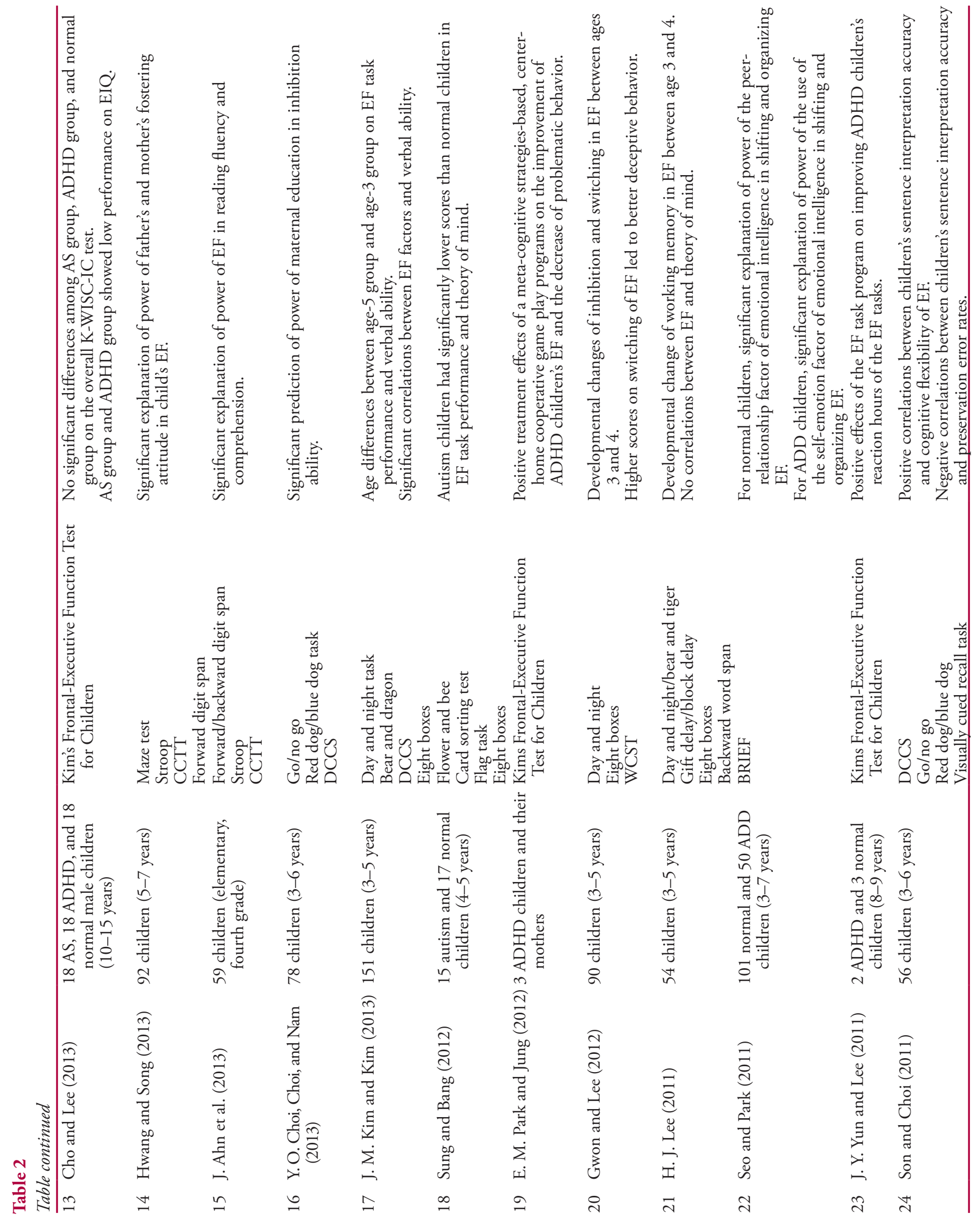




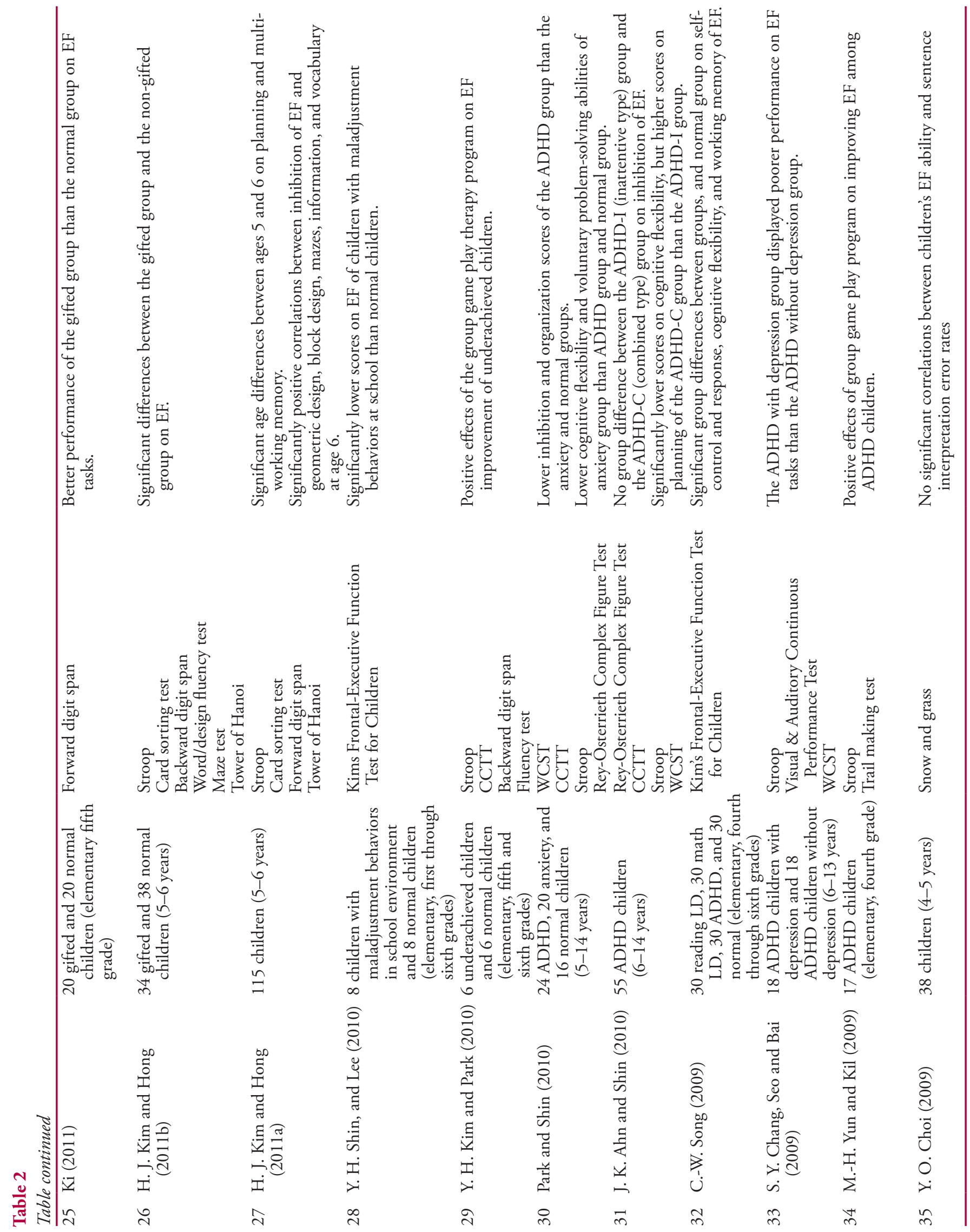




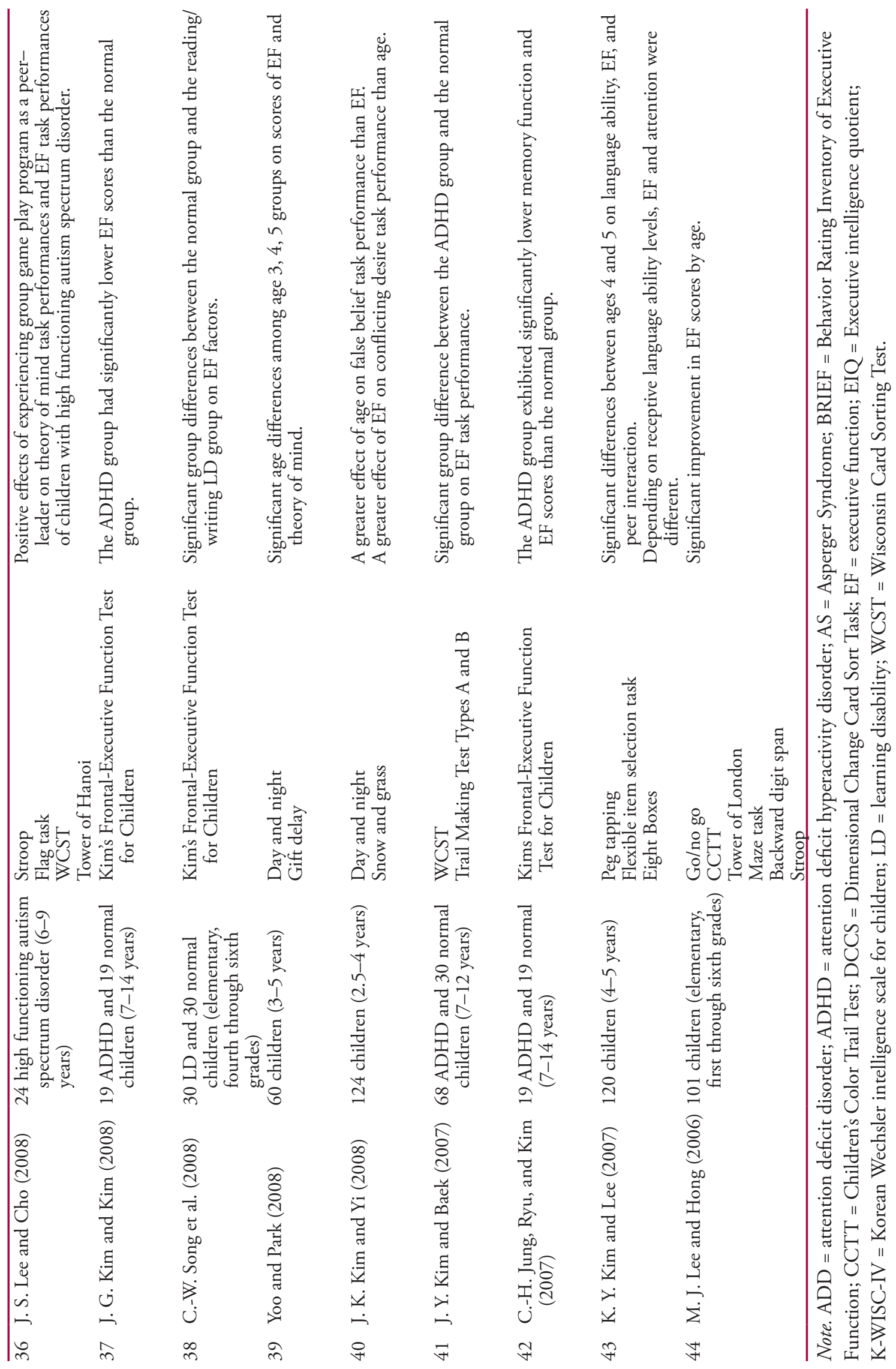


Table 3

Frequency of Studies in Journals

\begin{tabular}{|c|c|c|c|c|c|c|c|c|c|c|c|c|}
\hline Journal title & 2006 & 2007 & 2008 & 2009 & 2010 & 2011 & 2012 & 2013 & 2014 & 2015 & 2016 & $f$ \\
\hline Early Childhood Education Research \& Review & & & & & & & & & & 1 & 1 & 2 \\
\hline Korean Journal of Psychology & 1 & & 3 & 2 & 1 & 2 & 3 & 3 & 2 & 1 & 1 & 19 \\
\hline Korean Journal of Early Childhood Education & & & 1 & & & & & & & 1 & & 2 \\
\hline Korean Education Inquiry & & & & & & & & & & 1 & & 1 \\
\hline Journal of Korean Child Care and Education & & & & & & & & & & 1 & & 1 \\
\hline Korean Journal of Children's Media & & & & & & & & & & 1 & & 1 \\
\hline Korean Journal of Child Psychotherapy & & & & & & & & & 1 & & & 1 \\
\hline Korean Journal of Play Therapy & & & & & & & & & 2 & & & 2 \\
\hline Journal of Special Education: Theory and Practice & & & & & 1 & 1 & & & 1 & & & 3 \\
\hline Korean Society of Sport Psychology & & & & & & & & & 1 & & & 1 \\
\hline J. of Korean Home Management Association & & & & & & & & & 1 & & & 1 \\
\hline The Korean Journal Child Education & & & 1 & & & & 1 & 2 & & & & 4 \\
\hline Journal of Emotional \& Behavioral Disorders & & & & & 2 & & 1 & 1 & & & & 4 \\
\hline The Korean Journal of Rehabilitation Psychology & & & & & & & & 1 & & & & 1 \\
\hline Korean Journal of Child Studies & & & & & & & & 1 & & & & 1 \\
\hline The Korean Society of Community Living Science & & & & & & & & 1 & & & & 1 \\
\hline The Journal of Special Children Education & & & 1 & & & & 1 & & & & & 2 \\
\hline $\begin{array}{l}\text { Journal of Cognitive Enhancement and } \\
\text { Intervention }\end{array}$ & & & & & & 2 & & & & & & 2 \\
\hline $\begin{array}{l}\text { Journal of Special Education for Curriculum and } \\
\text { Instruction }\end{array}$ & & & & & & 1 & & & & & & 1 \\
\hline $\begin{array}{l}\text { The Journal of Korea Open Association for Early } \\
\text { Childhood Education }\end{array}$ & & & & & & 1 & & & & & & 1 \\
\hline Journal of Future Early Childhood Education & & 1 & & & & 1 & & & & & & 2 \\
\hline Korean Journal of Child \& Adolescent Psychiatry & 1 & & & & 1 & & & & & 1 & & 3 \\
\hline $\begin{array}{l}\text { Journal of the Korean Society of Biological } \\
\text { Therapies in Psychiatry }\end{array}$ & & 1 & & 1 & & & & & & & & 2 \\
\hline Family and Environment Research & & & & 1 & & & & & & & & 1 \\
\hline Korea Journal of Counseling & & 1 & & & & & & & & & & 1 \\
\hline Total & 2 & 3 & 6 & 4 & 5 & 8 & 6 & 9 & 8 & 8 & 2 & 60 \\
\hline
\end{tabular}

M. Park \& Shin, 2010). 두 번째로 많이 사용된 억제능력 측정 도구는 '낮과 밤' 과제이다. 낮과 밤 과제는 낮 또는 밤을 표현 하는 그림카드를 아동에게 보여주고, 아동이 제시된 그림카드 와 반대로 답하는 과제이다. 예를 들어, '낮' 그림카드를 제시 하면 ‘밤’이라고 말하고, ‘밤’ 그림카드를 제시하면 ‘낮’이라고 답하도록 하는 것이다(J. M. Kim \& Kim, 2013). 인지억제 측정
도구인 낮과 밤 과제와 비슷한 패턴으로 '토끼와 호랑이' 과제 는 토끼와 호랑이 손인형이 아동에게 행동을 지시할 때 토끼 가 지시하는 행동은 따라하고, 호랑이가 지시하는 행동을 따 라하지 않는 과제로서 아동의 행동억제를 측정하는 도구이다 (J. M. Kim \& Kim, 2013). 이러한 억제능력 측정도구가 연구 대상자의 연령이나 특성에 맞도록 '해와 달', '꽃과 벌' '양과 
Table 4

Assessment Tasks by Executive Function Factors

\begin{tabular}{|c|c|c|c|}
\hline Factors & Assessment tasks & $\mathrm{f}$ & $\%$ \\
\hline \multicolumn{4}{|l|}{ Tests } \\
\hline \multirow[t]{9}{*}{ Inhibition } & Stroop & 13 & 11 \\
\hline & Day and night & 11 & 8.5 \\
\hline & Go/no go & 4 & 3 \\
\hline & Flag task & 4 & 3 \\
\hline & Flanker & 3 & 2 \\
\hline & Pet tapping & 1 & 0.5 \\
\hline & Visual and auditory continuous performance test & 1 & 0.5 \\
\hline & Forward digit span & 1 & 0.5 \\
\hline & Total & 38 & 29 \\
\hline \multirow[t]{7}{*}{ Cognitive flexibility } & Wisconsin card sorting test & 9 & 7 \\
\hline & Children's color trail test & 7 & 5.5 \\
\hline & Dimensional change card sort task & 6 & 5 \\
\hline & Card sorting test & 8 & 6 \\
\hline & Trail making test & 3 & 2 \\
\hline & Flexible item selection task & 1 & 0.5 \\
\hline & Total & 34 & 26 \\
\hline \multirow[t]{9}{*}{ Working memory } & Six/eight boxes & 8 & 6 \\
\hline & Visually cued recall task & 1 & 0.5 \\
\hline & Wisconsin card sorting test & 1 & 0.5 \\
\hline & Trail making test & 1 & 0.5 \\
\hline & Children's color trail test & 1 & 0.5 \\
\hline & Corsi block & 1 & 0.5 \\
\hline & Zelazo Card Sort Task & 1 & 0.5 \\
\hline & Auditory working memory task & 1 & 0.5 \\
\hline & Total & 28 & 19.5 \\
\hline \multirow[t]{4}{*}{ Goal setting } & Maze test & 4 & 3 \\
\hline & Tower of Hanoi (London) & 8 & 6 \\
\hline & Rey-Osterrieth Complex Figure Test & 3 & 2 \\
\hline & Total & 15 & 11.5 \\
\hline Information process & Word/design fluency test & 3 & 2 \\
\hline Etc. & Kim's Frontal-Executive Function Test for Children & 8 & 6 \\
\hline \multirow[t]{3}{*}{ Batteries } & BRIEF & 5 & 4 \\
\hline & Children's EF deficits inventory & 3 & 2 \\
\hline & Total & 8 & 6 \\
\hline Total & & 134 & 100 \\
\hline
\end{tabular}

Note. duplicate frequency.

사자', '양과 호랑이', '사자와 토끼', '곰과 용' 등의 과제로 수정 되어 연구에 사용되었다(e.g., C.-Y. Kim \& Lim, 2013; Y.-J. Lee et al., 2014). 이 연구들이 낮과 밤 과제로 분류되어 본 연구에 서 분석되었다(11편; $8.5 \%)$. 이와 더불어 $\mathrm{Go} / \mathrm{NoGo}$ 과제도 억
제능력을 측정하는 대표적인 과제로 일컬어진다(5편; $3 \%)$. 숫 자 또는 문자 자극이 컴퓨터 모니터를 통해 제시되면, 아동은 표적자극이 제시될 때만 반응을 하고(컴퓨터 자판 누르기 등), 방해자극이 제시되면 반응을 하지 않도록 지시한 후 아동의 
수행결과를 측정하는 과제이다(M. J. Lee \& Hong, 2006).

인지적 유연성을 측정하는 도구로 많이 사용된 도구는 카 드분류과제이다. 가장 자주 사용되는 카드분류과제는 위스콘 신카드분류과제(Wisconsin Card Sorting Test)와 차원변경 카드 분류과제(Dimensional Change Card Sort Task)이다. 카드분류 과제는 서로 다른 색깔, 모양, 숫자가 그려진 여러 장의 카드 가 제시되면 아동은 과제의 규칙에 따라 카드를 분류하는 과 제이다(S. M. Park \& Shin, 2010). 본 연구에서는 위스콘신카 드분류과제(9편; $7 \%)$, 차원변경 카드분류과제(6편; $5 \%$ ), 기타 카드분류과제(8편; $6 \%$ )가 인지적 유연성을 측정하기 위해 사 용되었다. 그 다음으로 많이 사용된 도구는 아동 색 선로 검사 (Children's Color Trails Test)이다(7편; 5.5\%). 이 도구는 숫자만 을 순서대로 연결하는 단순 과제나 숫자를 순서대로 이어나감 과 동시에 색깔도 번갈아가면서 이어나가는 복합 과제가 포함 된다(S. M. Park \& Shin, 2010).

또 다른 실행기능 구성요소인 작업 기억을 측정하는 도구 중 국내 아동 실행기능 연구에서 가장 많이 사용된 것은 숫자/ 단어 거꾸로 외우기(13편; $10 \%$ )이다. 제시된 숫자나 단어를 거꾸로 외우거나 바로 따라 외우기 등의 과제 수행으로 작업 기억 중 정보 저장능력이나 최신화 능력을 측정하는 것이다 (H. J. Kim \& Hong, 2011a). 두 번째로 많이 사용된 작업 기억 측정도구는 상자 과제(8편; $6 \%$ )이다. 8 개 또는 6 개의 상자에 들어있는 자극(사탕 또는 초콜릿)을 찾아내는 과제이다. 한 상 자를 뒤집어 그 안의 사탕을 찾아내면 그 사탕을 끄집어내고 빈 상자를 다른 상자들과 함께 섞어 다시 아동에게 제시한 후, 아동이 다른 사탕을 찾도록 하는 과제이다(C.-Y. Kim \& Lim, 2013).

목표설정을 측정하는 도구로서 미로 찾기(4편; $3 \%$ )와 하노 이(런던) 탑(8편; $6 \%$ ) 과제가 많이 사용되었다. 미로 찾기 검사 는 제한시간 안에 미로의 탈출구를 찾아가는 과제이다. 하노 이 탑 또는 런던 탑 과제는 아동이 주어진 규칙에 따라 목표를 달성하기 위해 하노이/런던 탑 도구들을 옮기거나 완성하는 과제이다. 미로 찾기와 하노이/런던 탑 과제는 목표달성을 위 한 계획능력, 전략 생성 능력 및 전략적 수행능력 등을 측정한 다(H. J. Kim \& Hong, 2011b). 정보처리를 측정하는 도구는 단 어/도안 유창성 검사가 사용되었다(3편; $2 \%$ ). 단어의 초성만 아동에게 제시하고, 제시된 초성으로 시작하는 단어를 아동이 생각하여 말하게 하는 과제(단어 유창성 검사) 또는 몇 개의 점을 제시하고 점을 연결하여 다양한 도안을 만드는 과제(도 안 유창성 검사)를 통해 정보처리 능력을 측정한다(H. J. Kim $\&$ Hong, 2011b).
실행기능 측정도구 중에서 스트롭 과제나 $\mathrm{Go} / \mathrm{No} \mathrm{Go}$ 과제 는 순수 과제(pure task)로 한 가지 요소만(이 경우 억제능력 만 측정) 측정한다(Baggetta \& Alexander, 2016). 반면에 위스 콘신 카드분류검사는 몇 가지 구성요소를 측정하는 도구로 사용되었다. 예를 들어, S. M. Park과 Shin (2010)은 정상아동, $\mathrm{ADHD}$ 아동, 불안장애 아동의 실행기능을 비교함에 있어 인 지적 유연성과 작업기억 능력을 측정하는 도구로서 위스콘 신 카드분류검사가 사용하였다. 이러한 검사는 과제 혼합 문 제(task impurity problem)를 측정하는 것으로 하나의 측정도구 로 1 개 이상의 실행기능 하위영역을 측정하였다(Baggetta \& Alexander, 2016). 실행기능의 다른 구성요소를 효과적으로 측 정하기 위해 적절한 측정도구를 사용하는 것은 무엇보다 중요 할 것이다.

위에서 언급한 측정도구 외에 아동용 Kim's 전두엽-관리 기능 신경심리검사(Kim's Frontal-Executive Function Test for Children)가 국내 아동 실행기능 연구에서 간헐적으로 사용된 것으로 나타났다(8편; $6 \%$ ). 이 검사는 4개의 소검사(스트롭 검 사, 단어유창성 검사, 도안유창성 검사, 인출효율성 검사)로 구 성되어 있고 각 주의능력, 언어능력, 시공간능력, 기억능력을 측정한다(J. G. Kim \& Kim, 2008). 아동용 Kim's 전두엽-관리기 능 신경심리검사는 우리나라 실정에 맞도록 국내에서 개발된 표준화된 검사도구라는 것에 큰 의의가 있다. 아동용 Kim's 전 두엽-관리기능 신경심리검사는 $\mathrm{ADHD}$ 아동(Cho \& Lee, 2013; C.-H. Jung et al., 2007; J. G. Kim \& Kim, 2008; E. M. Park \& Jung, 2012), 학교부적응 아동(Y. H. Shin et al., 2010), 학습장애 아동(C.-W. Song 2009) 등을 대상으로 한 연구에 사용되었다.

실행기능을 측정하는 질문지는 실행기능 행동평정척도 (Behavior Rating Inventory of Executive Function, 5편, 4\%)와 아 동용 실행기능 결함 설문지(3편, $2 \%$ )가 사용되었다. 실행기능 행동평정척도는 아동의 실행기능을 측정하기 위한 부모나 교 사용 설문지이다. 감정조절, 작업기억, 억제, 주의전환, 계획조 직을 측정하는 총 63 문항으로 구성되었다 $(\mathrm{H} . \mathrm{W} . \mathrm{Park} \& \mathrm{Lee}$, 2013). 또 다른 설문지인 아동용 실행기능 결함 설문지는 국내 에서 개발된 측정도구로서(J. R. Park \& Song, 2012), 주의집중, 전환, 계획 및 조직화, 행동 및 정서조절을 측정하는 자기보고 식 질문지이다.

위에서 살펴 본 실행기능 측정도구들 중 국내 연구자들이 개발한 측정도구인 아동용 Kim's 전두엽-관리기능 신경심리 검사와 아동용 실행기능 결함 설문지를 사용한 논문의 개수는 국외에서 개발된 측정도구를 사용한 논문 수와 비교하면 현저 히 작은 것을 알 수 있다. 국제적으로 많이 사용되어 신뢰도가 
검증된 실행기능 측정도구를 사용하는 것도 연구적 의미가 있 지만, 국내에서 개발된 측정도구를 사용하여 유의미한 결과를 도출해내는 연구가 증가한다면 국내 실행기능 연구 측정도구 개발이 더 활성화될 것으로 기대한다.

\section{아동 실행기능 연구의 내용 동향}

\section{연령 및 연구대상 특성별 실행기능 비교}

최근 아동 실행기능 연구의 내용을 분석해 본 결과, 연구대상 자 연령 또는 특성별 실행기능 수행 비교 연구가 다수를 차지 하였다. 연령별 실행기능 수행을 비교한 연구를 통해 연령별 아동의 실행기능 수행 차이와 연령의 증가에 따른 실행기능 의 발달을 살펴본 연구가 많았다(11편). 예를 들어, H. W. Park 과 Lee (2013)가 3-7세 일반 아동 124명을 대상으로 아동의 연 령별 실행기능 수행을 비교하는 연구 결과로서, 실행기능 수행 의 연령별 차이가 있음을 제시하였다. E. Choi와 Song (2013)은 $3-5$ 세 일반 아동 104 명을 대상으로 아동의 인지적 실행기능과 정서적 실행기능의 연령별 차이를 연구하였다. 그 결과 연령별 로 인지적 및 정서적 실행기능의 발달패턴에 차이가 있음을 보 여 주였다. 아동의 인지적 실행기능은 만 3-4세에 유의하게 증 가하였고, 정서적 실행기능은 만 $3,4,5$ 세 간 연령별 차이가 유 의하였다. 또한, 인지적 및 정서적 실행기능과 인지적 자기조 절의 관계를 분석한 결과, 연령이 증가할수록 인지적 및 정서 적 실행기능의 상-하 집단의 인지적 자기조절이 유의하게 차이 나는 것으로 나타났다. 앞의 두 연구가 전 학령기 아동을 대상 으로 한 반면, M. J. Lee와 Hong (2006)은 학령기 아동을 대상 으로 연령별 실행기능 수행 차이를 연구하였다. 초등하교 1-6 학년생 101 명을 대상으로 그들의 실행기능 하위영역(작업기 억, 전환능력, 억제능력)을 측정한 결과, 연령이 증가할수록 그 하위영역 과제 수행이 유의미하게 증가함을 알 수 있어 연령에 따른 실행기능의 발달을 나타낸다고 할 수 있다.

아동 특성별 실행기능 비교를 연구한 논문은 일반 아동과 비일반 아동의 실행기능 수행을 비교하거나 특성이 다른 비일 반 아동 간의 실행기능 수행을 비교하는 연구도 활발하게 수 행되었다(21편). 예를 들어, M. S. Shin 등(2006)은 ADHD 아 동 16 명, 아스퍼거 장애 아동 14 명, 학습 장애 아동 16 명을 대 상으로 세 집단 간 실행기능을 비교하는 연구를 실시하였다. 공변량분석(ANCOVA)으로 자료를 분석한 결과, 학습 장애 아 동이 아스퍼거 장애 아동과 $\mathrm{ADHD}$ 아동에 비해 상식, 어휘력, 숫자외우기 과제 등에서 가장 낮은 수행능력을 보였다. 또한,
인지적 유연성을 측정하는 위스콘신 카드 분류 과제 수행에서 세 집단 간 유의한 차이가 있었고, $\mathrm{ADHD}$ 아동이 가장 낮은 점수를 보였다. 주의력과 인지세트 변경을 측정한 선로 잇기 검사-B형과 조직화 능력을 측정하는 Rey-Osterrieth 복합도형 검사 수행에서 세 집단 간 유의한 차이가 없었지만, 이 세 집단 의 실행기능 과제 수행 점수는 정상집단 수행점수보다 부진하 였다(정상집단의 하위 $25 \%$ 이하). C.-W. Song (2009)은 일반아 동, 읽기 및 수학 학습장애 아동, $\mathrm{ADHD}$ 아동 각 30 명을 대상 으로 그들의 의 실행기능 수행의 차이를 아동용 Kim's 전두엽관리기능 신경심리검사를 사용하여 연구하였다. 그 결과 억제 능력을 측정하는 스트롭 검사에서 $\mathrm{ADHD}$ 아동이 가장 부진 한 수행점수를 보였고, 인지적 유연성을 측정하는 단어/도안 유창성 검사에서 학습장애 아동이 저조한 성적을 나타냈다. 작업 기억을 측정하는 인출 효율성 검사에서 학습장애 아동이 가장 낮은 점수를 보였다. 정상아동 집단은 모든 영역에서 가 장 높은 수행점수를 보였고, 각 집단 간 유의한 차이를 보인 것 으로 나타났다. 이 연구 사례들에도 나타나듯이, 비일반 아동 이 가지고 있는 다른 특성에 따라 실행기능의 다른 하위영역 에서 취약점을 가지는 것을 알 수 있다. 그러므로 대상자의 특 성에 맞는 실행기능 향상 프로그램 개입이 필수적이고 이를 위해 중재/교육 프로그램 개발 및 적용 연구가 우선되어야 할 것이다.

\section{학습 관련 실행기능 연구}

최근 국내 아동 실행기능 연구에서 나타나는 특징은 실행기 능과 학습의 관계를 연구한 논문이 증가하고 있다는 것이다(7 편). 1999년부터 2005년까지 수행된 실행기능 연구의 동향 분 석을 보면(C.-W. Song \& Byun, 2007), 임상적 장면에서 비일 반 아동의 실행기능 결함 등에 초점을 맞추었던 경향성을 알 수 있다. 하지만, 본 연구에서 분석한 결과, 이러한 연구 경향 이 점점 일반아동의 학습, 학교생활, 사회생활 등과 관계를 이 해하려는 연구로 범위를 확장하고 있음을 알 수 있다. 최근에 수행된 연구들을 살펴보면, Y. S. Kim과 Kwak (2014)은 4세 일 반 아동 110 명의 실행기능이 2 년 후 6 세가 되었을 때의 읽기 유창성과 이해도에 미치는 영향을 연구하였다. 실행기능의 하 위영역인 억제, 인지적 유연성, 작업기억이 4세 때 측정되었 고, 2년 후 6세 때 문장 읽기 유창성과 이해도가 측정되었다. 그 결과, 4 세 때의 실행기능 하위영역들 중 작업기억이 6세 때 읽기 유창성을 유의미하게 예측하고, 4 세 때의 억제능력과 인 지적 유연성이 6세 때 읽기 이해도에 유의미하게 영향을 주었 
다. J. Ahn, Bang과 Park (2013)은 초등 4학년생 59명을 대상으 로 그들의 읽기능력(읽기 유창성, 읽기 이해력)에 실행기능의 하위영역(억제능력, 작업기억, 전환능력)이 미치는 영향을 연 구하였다. 위계적 회귀분석을 통하여 자료를 분석한 결과, 그 들의 읽기 유창성에 대하여 억제능력과 작업기억이 유의한 설 명력을 가졌고, 읽기 이해력에 대해서는 전환능력과 억제능력 이 유의한 설명력을 가지는 것으로 나타났다. Maeng 등(2014) 는 만 8-11세의 학령기 아동 195명의 실행기능 하위요인(억 제능력과 전환능력)과 그들의 수학문제 해결능력 간의 관계 를 연구하였다. 그 결과, 아동의 전환능력은 그들의 수학적 능 력과 유의한 상관관계를 보이는 것으로 나타났다. 아동의 학 습과 실행기능의 관련성을 연구하는 논문의 증가는 국제적 연 구 동향과 그 방향성을 같이 하고 있다. 최근 국외 실행기능 연 구에서 아동의 실행기능과 수학문제 해결력 및 수학 학업성취 도(Agostino et al., 2010; Clark et al., 2010), 읽기능력(Chung \& McBride-Chang, 2011; Foy \& Mann, 2013), 과학 학습력(Rhodes et al., 2014) 등 학업수행 능력과 실행기능 간 관련성 연구가 증 가하는 추세이다.

최근 수학이나 읽기 등 특정 교과목에 대한 연구의 증가 와 더불어 자기조절 및 자기 주도적 학습과 실행기능의 관계 를 살펴보는 연구가 국제적으로 점차 증가하였다. 실행기능 을 자기조절의 한 과정으로 생각하거나(Beck, Schaefer, Pang, \& Carlson, 2011; Dilworth-Bart, 2012), 실행기능이 자기조절 에 중요한 영향을 준다고(Bridgett, Oddi, Laake, Murdock, \& Bachmann, 2013) 주장하는 등 실행기능과 자기조절 간의 관계 에 대한 학문적 관심은 꾸준하게 증가하고 있다. 실행기능과 자기조절이 긴밀한 관계가 있다고 본다면, 학교생활이나 학습 상황에 적절하게 적응하기 위해 스스로의 정서, 인지, 행동을 조절할 수 있도록 하는 실행기능이나 자기조절의 역할이 성공 적 학업 수행 또는 효율적 학습을 하도록 영향을 줄 수 있을 것 이다(Baggetta \& Alexander, 2016). 이러한 국제적 연구 추세에 따라 국내에서도 자기조절 및 자기 주도적 학습과 실행기능 간 관계를 연구하는 논문이 출판되기 시작한다. 최근 국내 연 구의 경우를 살펴보면, M.-R. Song과 $\mathrm{Ha}$ (2014)는 초등학교 고 학년 학생들을 대상으로 실행기능 결함이 자기 주도적 학습능 력에 미치는 영향을 연구하였다. 이 연구에서 실행기능의 결 함은 자기 주도적 학습능력의 하위요인인 학습계획과 학습실 행에 유의하게 부정적 영향을 주는 것으로 나타났다. E. Choi 와 Song (2013)은 만 3-5세 아동의 인지적 실행기능, 정서적 실 행기능, 자기조절력 간의 관계를 연구하기 위해 그들의 인지 적/정서적 실행기능 수행능력을 측정하여 상-하 집단으로 구
분 한 후 각 집단의 인지적 자기조절력과 행동적 자기조절력 을 살펴보았다. 그 결과, 연령이 증가할수록 두 집단 간의 인지 적 자기조절의 차이가 유의하게 커짐이 확인되었다. 연령이 증가할수록 인지적/정서적 실행기능 수행이 우수한 아동들 (상 집단)이 우수하지 않은 아동들(하 집단)보다 자신의 인지 과정과 행동을 잘 조절한다고 나타났다. 실행기능과 학습 및 학업 수행에 관한 연구의 증가는 아동의 학습능력에 대한 이 해와 효율적 학습을 이끌어 내기 위한 중요한 과정이므로 다 양한 학습자의 실행기능과 학습에 대한 연구가 더 증가되어야 할 것이다.

\section{실행기능과 다양한 변인 간 관계 연구}

실행기능이 인간의 사고과정과 행동 수행에서 중심적 역할을 하기 때문에, 아동의 실행기능이 다양한 인지적, 행동적, 사회 적 변인들과 관련성 및 영향 연구가 많이 수행되었다. 아동 실 행기능과 관련성을 연구함에 있어 가장 많이 연구된 인지적 변인은 마음이론(theory of mind)과 관련하여 이루어졌다. 마 음이론은 “사람들의 행동 이해는 의도, 바람, 믿음과 같은 마 음상태 추론에 기반을 둔다(H. J. Lee, 2011, p.99).”라고 주장 하고 있다. 마음 상태의 이해가 약 3-5세 경 큰 폭으로 발달을 한다고 보고되었고(Wellman, Cross, \& Watson, 2001), 이는 실 행기능의 발달과 시기가 겹치고 있다(H. J. Lee, 2011). 이러한 이유로 많은 실행기능 연구에서 마음이론과 실행기능 간 관 계 규명에 집중하였다. Y. M. Lee와 Park (2008)은 3-5세 아동 을 대상으로 차원변경 카드 분류 과제를 사용해 실행기능 향 상 훈련을 실시 한 후 틀린 믿음에 대한 이해(행위자의 믿음 에 근거하여 행위자의 행동을 해석하거나 예측하는 능력)가 훈련 전보다 향상된 것으로 보고했다. J. K. Kim과 Yi (2008)는 만 2.5-4세 아동 124 명 대상으로 한 연구에서 실행기능이 틀 린 믿음 과제 수행능력에 유의한 설명력을 가지는 것을 밝혀 냈다. 이처럼 실행기능과 마음이론 간의 긍정적 관계를 확인 한 연구가 있는 반면, 이와 반대되는 연구결과도 있다. 예를 들 어, H. J. Lee (2011)는 유치원에 재원 중인 3-5세 한국 아동을 대상으로 그들의 마음이론과 실행기능의 발달 및 관계를 연구 하였다. 아동의 마음이론을 측정하기 위해 틀린 믿음 과제를 사용하였고, 실행기능을 측정하기 위해 억제와 작업 기억 측 정과제를 사용하였다. 그 결과, 마음이론 과제 수행과 실행기 능 과제 수행과 유의한 상관관계를 보이지 않았다. 이처럼 상 이한 연구결과가 나오는 경우가 발생하기 때문에 다양한 연령 및 특성의 연구대상자를 연구에 포함시키는 것이 필요하고, 
다른 연령이나 특성에 맞는 중재/교육 프로그램 개발 등에 적 용할 수 있도록 하는 조치가 필요할 것이다.

실행기능과 아동의 학교생활이나 사회적 활동 간 관계를 살펴보는 연구도 증가하고 있다. 실행기능과 또래관계의 관계 (Chun, 2014), 실행기능과 스마트폰의 관계(Oh \& Ha, 2014), 아동의 실행기능과 교육기관 적응의 관계(No \& Park, 2011) 등 학업과의 관련성을 넘어 사회적 기술이나 생활과 연관된 연구가 최근 등장하고 있다. 또한, 부모의 양육태도와 아동의 실행기능의 관계(Hwang \& Song, 2013; Kong \& Lim, 2011; Y.J. Lee et al., 2014)와 운동과 실행기능의 관계 연구가 최근 새로 운 연구주제로 나타났다(H.-Y. Jung \& Choi, 2014; Y. A. Lee \& Lee, 2015). Y. A. Lee와 Lee (2015)는 4-5세 아동을 대상으로 운 동능력과 실행기능 과제 수행 간 유의한 상관관계가 있음을 확인하였다. H.-Y. Jung과 Choi (2014)는 8주간 유산소 운동 프 로그램을 $\mathrm{ADHD}$ 아동에게 실행 한 결과 $\mathrm{ADHD}$ 아동의 실행 기능이 프로그램 참여 전 보다 향상된 것으로 나타났다고 보 고했다. 이처럼 최근 다양한 영역과 실행기능의 관계를 살펴 보는 연구가 증가하는 추세는 국제 실행기능 연구 추세와 일 치하고 있다(e.g., Davis et al., 2011; Hughes \& Ensor, 2009). 또 한, 아동의 실행기능과 다양한 변인과 관계를 연구하는 것은 실행기능과 아동의 인지, 정서, 행동 및 환경과의 연결성을 이 해하고 실행기능의 중요한 역할을 발견하는 연구적 의미가 크 다고 볼 수 있다.

\section{정서적 실행기능과 인지적 실행기능 연구}

최근에는 실행기능을 정서적 실행기능(hot $\mathrm{EF}$ )와 인지적 실행 기능(cool EF)으로 구분하여 행해지는 연구도 증가하는 추세 이다(e.g., E. Choi \& Song, 2013; Prencipe et al., 2011). 국내에서 도 2012년에 정서적 실행기능과 인지적 실행기능에 대한 첫 연구가 출판되었고(Kong \& Lim, 2011), 2016년까지 6편의 연 구가 더 출판되었다. 정서적 실행기능은 동기 및 정서가 발생 하는 상황에서 요구되는 실행기능으로서 사회능력, 친사회적 기술, 또래관계 등과 관련이 있고, 인지적 실행기능은 의식적 사고과정 조절을 의미하며 인지적 문제 해결과 관계있는 실행 기능이다(Zelazo \& Carlson, 2012). 국내 연구에서 인지적 실행 기능과 정서적 실행기능을 측정하는 도구를 살펴보면, 인지적 실행기능은 낮과 밤 과제나 카드분류과제처럼 위에서 언급했 던 억제, 인지적 유연성, 작업 기억 등을 측정하는 도구가 사용 되었다. 정서적 실행기능을 측정하는 도구는 보상이나 만족을 즉시 받고 싶은 욕구 억제 또는 정서 조절을 측정하는 보상/
만족 지연과제가 사용되었다. 본 연구에서 분석한 결과, 정서 적 실행기능을 측정하기 위하여 역보상 과제(2편), 상자/스티 커 찾기 과제(2편), 선물/과자 지연 과제(5편), 아동도박과제(3 편) 등이 사용되었다. 인지적 실행기능을 측정하기 위하여 낮 과 밤 과제(2편), 6 개/8개 상자 과제(2편), 차원 변경 카드 분류 과제(1편)가 사용되었다. 국내에서 정서적 실행기능과 인지적 실행기능에 대한 연구를 살펴보면, Chi와 $\operatorname{Kim}$ (2016)은 만 5세 일반 아동 180 명을 대상으로 그들의 정서적 실행기능, 인지처 리능력, 자기조절력, 마음이론 간 관계를 상관분석과 단계적 중다회귀분석을 통하여 살펴보았다. 그 결과, 아동의 정서적 실행기능은 그들의 인지처리능력, 자기조절력, 마음이론과 유 의한 정적 상관관계를 보였고, 정서적 실행기능의 가장 강력 한 설명변인은 인지처리능력이었다. Cha (2015)는 만 4-5세 아동과 그들의 어머니 78 쌍을 대상으로 한 연구에서 아동의 인지적 실행기능에 아동에 대한 어머니의 자율적 지원과 적절 한 비계설정이 유의한 정적 영향을 주는 것으로 나타났다.

정서적 실행기능과 인지적 실행기능 관련 연구는 최근에 국내/외에서 꾸준히 증가하고 있고 앞으로도 국제적으로 연 구적 관심을 많이 받을 것으로 예상한다. 국제적 연구 추세를 따르는 것과 함께 한국 사회에서 중요하게 고려되는 아동 관 련 이슈들과 아동의 정서적/인지적 실행기능의 관계 관련 연 구 주제에 대한 연구자들의 관심이 필요다고 생각한다.

\section{실행기능 중재 프로그램 관련 연구}

실행기능을 향상을 위한 교육 및 중재 프로그램의 영향을 연 구한 연구들은 주로 실행기능이 낮다고 보고되는 비일반 아 동을 대상으로 이루어 졌다. 가장 많이 사용된 연구 대상자는 $\mathrm{ADHD}$ 아동이다. $\mathrm{ADHD}$ 아동을 대상으로 실행기능 향상을 위해 상위 인지전략 중심의 가정연계 게임놀이 프로그램(E. M. Park \& Jung, 2012), 집단게임 놀이 프로그램(M.-H. Yun \& $\mathrm{Kil}, 2009)$, 충동억제, 계획능력 향상, 작업 기억 향상 등의 내 용으로 구성된 실행기능 향상 프로그램(J. Y. Yun \& Lee, 2011) 등을 실시하고 효과를 검증하는 연구들이 보고되었다. 그 외 에도 학습부진 아동을 대상으로 한 집단게임 놀이 프로그램 (Y. H. Kim \& Park, 2010)이 수행되었다. 이와 같이 국내의 실 행기능 향상 프로그램에 대한 연구는 비일반 아동을 대상으 로 하는 연구가 다수를 이루고 일반아동을 대상으로 한 연구 는 아직 미진한 상태이다. 국외 연구의 경우, 비일반 아동 대 상으로 한 연구뿐만 아니라 전 학령기 일반 아동(e.g., Bierman, Nix, Greenberg, Blair, \& Domitrovich, 2008; Thorell, Lindqvist, 
Nutley, Bohlin, \& Klingberg, 2009)이나 학령기 일반 아동(e.g., Kloo \& Perner, 2008)을 대상으로 한 연구가 이루어지고 있는 것과 비교하면 최근 10 년 사이에 국내에서 일반 아동을 대상 으로 한 실행기능 향상 프로그램 적용 연구는 전무한 상태이 다. 국제적으로 일반 아동의 자기조절 및 학교생활 등과 관련 된 사회적 기능에 대한 실행기능 연구가 증가하는 추세이므 로, 그들을 대상으로 실행기능 향상 프로그램을 개발하고 적 용하는 노력이 국내에서도 더욱 필요할 것이다.

\section{실행기능 측정도구 개발 연구}

최근 국내 아동 실행기능 측정도구 연구는 아동용 실행 기능 결함 질문지를 개발 및 타당화 연구(J. R. Park \& Song, 2012)로 단 1 편에 불과하다. 이 연구에서 개발된 질문지는 실행기능을 주의통제와 목표지향, 두 가지 상위요인으로 선정 한 후 주의 통제의 하위요인으로 주의집중과 전환, 목표지향의 하위요인 으로 계획 및 조직화, 행동 및 정서조절을 선정 한 후 각 하위요 인에 대한 자기보고식 문항들을 개발하였다. 이 실행기능 결함 질문지는 현재까지 2편의 논문에 사용되었다(Chun, 2014; M. -R. Song \& Ha, 2014). 대다수 국내 아동 실행기능 연구들이 서 구에서 개발된 검사나 질문지를 사용하여 연구를 진행했다. 물 론, 국제적으로 신뢰도와 타당도가 검증된 측정도구를 사용하 는 것도 정확한 연구 수행을 위해 적절하지만, 측정도구 개발 및 적용도 간과하지 말아야 할 연구 분야일 것이다.

\section{논의 및 결론}

실행기능은 다양한 심리학 분야(인지, 발달, 교육, 신경 심리 학 등)에서 가장 많이 인용되는 개념 중에 하나이고(Toplak, West, \& Stanovich, 2013), 특히 아동의 실행기능은 그들의 발 달 및 학습과 맞물려 더욱 관심이 증가되고 있다. 향후 아동 실 행기능 연구에 박차를 가하기 위해 최근 연구 동향 이해는 중 요한 기초 자료가 될 것이므로, 본 연구는 최근 10 년 간 국내 학술지에 출판된 아동 실행기능 연구의 연구대상, 연구방법, 연구주제 등을 살펴보았다. 최근 국내 아동 실행기능 연구를 살펴본 결과에 따른 제안점은 다음과 같다. 첫째, 아동의 연령 별 실행기능 비교나 비일반 아동의 실행기능과 비교하는 수준 에 머물러 있는 연구가 많았다(e.g., H. W. Park \& Lee, 2013; C.W. Song, 2009). 연령별 또는 특성별 비교 연구는 초기 실행기 능 연구의 형태이고, 이러한 초기 연구결과를 바탕으로 좀 더
진화된 연구가 향후 수행되어야 할 것이다. 또한, 특성별 비교 연구의 경우, 연구대상을 확장하는 노력이 필요할 것이다. 현 재까지 다문화 배경 아동이나 영재아동 대상 연구(H. J. Kim \& Hong, 2011b; C.-Y. Kim \& Lim, 2013) 등, 한국의 교육적 및 사회적 문제에 포함되는 아동 대상 연구가 이루어져 왔다. 하 지만, 그 수가 아주 미미하므로 향후 다양한 특성을 가진 아동 의 실행기능에 대한 연구가 더욱 증가되어야 할 것이다. 둘째, 아동의 실행기능과 학습 관련 연구의 증가와 함께 아동의 자 기조절과 실행기능에 대한 연구가 지속적으로 수행되어야 할 것이다. 아동의 학습과 자기조절을 실행기능과 연결하는 연구 가 국제적으로는 학문적 관심을 많이 받고 있지만, 국내 연구 에서는 아직 미진한 상태이다. 국제적 연구 추세에 맞추어 한 국 아동의 실행기능과 자기조절 학습에 대한 연구자들의 관심 이 더욱 필요할 것이다. 셋째, 비일반 아동만을 대상으로 하는 실행기능 향상 중재 프로그램 개발 및 적용 연구에 머물러 있 는 상태이다. 일반 아동의 실행기능 연구가 증가하는 만큼 그 연구결과를 실제적으로 적용할 수 있는 일반 아동 대상 중재 프로그램 개발 및 적용 연구가 증가되어야 할 것이다. 넷째, 국 내 연구자들의 실행기능 측정도구 개발에 대한 학문적 관심이 절실한 상태이다. 현재까지 한국에서 개발될 측정도구는 단 2 건에 불과하고(아동용 Kim's 전두엽-관리기능 신경심리검사, 아동용 실행 기능 결함 질문지), 많은 연구에서 사용되지도 않 고 있다. 실행기능 연구를 위한 측정도구 개발 및 적용에 대한 연구가 증가하는 것은 탄탄한 실행기능 연구 토대를 만드는 것에 크게 기여할 것으로 기대되므로 학문적 관심이 지속되어 야 할 것이다. 본 연구의 제한점은 실행기능과 관련된 다양한 단어 및 변인이 문헌검색에서 사용되지 않았다는 것이다. 실 행기능과 유사어인 ‘집행기능'이나 ‘중앙처리기능', 또는 실행 기능 변인인 ‘억제’나 ‘작업 기억' 등 단어를 사용한 문헌검색 이 이루어지지 않아 이 단어들을 제목이나 주제어로 사용한 실행기능 연구논문이 누락되었을 가능성을 배제할 수 없다. 본 연구에서 살펴본 것처럼 아동의 실행기능에 대한 연구가 크게 증가하고 다양한 영역으로 확대되는 추세이다. 그러므로 본 연구가 향후 아동 실행기능 연구를 실행하기 위한 기초자 료로 사용될 수 있기를 기대한다.

\section{Conflict of Interest}

No potential conflict of interest relevant to this article was reported. 


\section{References}

\section{In English}

Agostino, A., Johnson, J., \& Pascual-Leone, J. (2010). Executive functions underlying multiplicative reasoning: Problem type matters. Journal of Experimental Child Psychology, 105(4), 286-305. doi:10.1016/j.jecp.2009.09.006

Anderson, P. J., \& Reidy, N. (2012). Assessing executive function in preschoolers. Neuropsychology Review, 22(4), 345-360. doi: $10.1007 /$ s11065-012-9220-3

Baggetta, P., \& Alexander, P. A. (2016). Conceptualization and operationalization of executive function. Mind, Brain, and Education, 10(1), 10-33. doi: 10.1111/mbe.12100

Beck, D. M., Schaefer, C., Pang, K., \& Carlson, S. M. (2011). Executive function in preschool children: Test-retest reliability. Journal of Cognition and Development, 12(2), 169-193. doi:10. 1080/15248372.2011.563485

Bierman, K. L., Nix, R. L., Greenberg, M. T., Blair, C., \& Domitrovich, C. E. (2008). Executive functions and school readiness intervention: Impact, moderation, and mediation in the Head Start REDI program. Development and Psychopathology, 20(3), 821-843. doi:10.1017/S0954579408000394

Blair, C., \& Diamond, A. (2008). Biological processes in prevention and intervention: The promotion of self-regulation as a means of preventing school failure. Development and Psychopathology, 20(3), 899-911. doi:10.1017/S0954579408000436

Bridgett, D. J., Oddi, K. B., Laake, L. M., Murdock, K. W., \& Bachmann, M. N. (2013). Integrating and differentiating aspects of self-regulation: Effortful control, executive functioning, and links to negative affectivity. Emotion, 13(1), 47-63. doi:10.1037/a0029536

Brydges, C. R., Reid, C. L., Fox, A. M., \& Anderson, M. (2012). A unitary executive function predicts intelligence in children. Intelligence, 40(5), 458-469. doi:10.1016/j.intell.2012.05.006

Chung, K. K., \& McBride-Chang, C. (2011). Executive functioning skills uniquely predict Chinese word reading. Journal of Educational Psychology, 103(4), 909-921. doi:10.1037/ a0024744

Clark, C. A., Pritchard, V. E., \& Woodward, L. J. (2010). Preschool executive functioning abilities predict early mathematics achievement. Developmental Psychology, 46(5), 1176-1191. doi: $10.1037 / \mathrm{a} 0019672$

Davis, C. L., Tomporowski, P. D., McDowell, J. E., Austin, B. P., Miller, P. H., Yanasak, N. E.,. . . Naglieri, J. A. (2011). Exercise improves executive function and achievement and alters brain activation in overweight children: A randomized, controlled trial. Health Psychology, 30(1), 91-98. doi:10.1037/ a0021766
Diamond, A. (2006). The early development of executive functions. In E. Bialystok \& F. I. M. Craik (Eds.), Lifespan cognition: Mechanisms of change (pp. 70-95). New York: Oxford University Press.

Diamond, A. (2013). Executive functions. Annual Review of Psychology, 64, 135-168. doi:10.1146/annurevpsych-113011-143750

Dilworth-Bart, J. E. (2012). Does executive function mediate SES and home quality associations with academic readiness? Early Childhood Research Quarterly, 27(3), 416-425. doi:10.1016/ j.ecresq.2012.02.002

Duncan, J., Johnson, R., Swales, M., \& Freer, C. (1997). Frontal lobe deficits after head injury: Unity and diversity of function. Cognitive Neuropsychology, 14(5), 713-741. doi:10.1080/026432997381420

Foy, J. G., \& Mann, V. A. (2013). Executive function and early reading skills. Reading and Writing, 26(3), 453-472. doi:10.1007/s11145-012-9376-5

Hughes, C. H., \& Ensor, R. A. (2009). How do families help or hinder the emergence of early executive function? New Directions for Child and Adolescent Development, 2009(123), 35-50. doi: $10.1002 / \mathrm{cd} .234$

Jurado, M. B., \& Rosselli, M. (2007). The elusive nature of executive functions: A review of our current understanding. Neuropsychology Review, 17(3), 213-233. doi:10.1007/ s11065-007-9040-z

Kaplan, S., \& Berman, M. G. (2010). Directed attention as a common resource for executive functioning and selfregulation. Perspectives on Psychological Science, 5(1), 43-57. doi:10.1177/1745691609356784

Kloo, D., \& Perner, J. (2008). Training theory of mind and executive control: A tool for improving school achievement? Mind, Brain, and Education, 2(3), 122-127. doi:10.1111/ j.1751-228X.2008.00042.x

Miyake, A., Friedman, N. P., Emerson, M. J., Witzki, A. H., Howerter, A., \& Wager, T. D. (2000). The unity and diversity of executive functions and their contributions to complex "frontal lobe" tasks: A latent variable analysis. Cognitive Psychology, 41(1), 49-100. doi:10.1006/ cogp.1999.0734

Nota, L., Soresi, S., \& Zimmerman, B. J. (2004). Self-regulation and academic achievement and resilience: A longitudinal study. International Journal of Educational Research, 41(3), 198-215. doi:10.1016/j.ijer.2005.07.001

Prencipe, A., Kesek, A., Cohen, J., Lamm, C., Lewis, M. D., \& Zelazo, P. D. (2011). Development of hot and cool executive function during the transition to adolescence. Journal of Experimental Child Psychology, 108(3), 621-637. doi:10.1016/j.jecp.2010.09.008

Rhodes, S. M., Booth, J. N., Campbell, L. E., Blythe, R. A., Wheate, N. J., \& Delibegovic, M. (2014). Evidence for a 
role of executive functions in learning biology. Infant and Child Development, 23(1), 67-83. doi:10.1002/icd.1823

Richland, L. E., \& Burchinal, M. R. (2013). Early executive function predicts reasoning development. Psychological Science, 24(1), 87-92. doi:10.1177/0956797612450883

Rueda, M. R., Posner, M. I., \& Rothbart, M. K. (2005). The development of executive attention: Contributions to the emergence of self-regulation. Developmental Neuropsychology, 28(2), 573-594. doi:10.1207/s15326942dn2802_2

Thorell, L. B., Lindqvist, S., Bergman Nutley, S., Bohlin, G., \& Klingberg, T. (2009). Training and transfer effects of executive functions in preschool children. Developmental Science, 12(1), 106-113. doi:10.1111/j.14677687.2008.00745.x

Toplak, M. E., West, R. F., \& Stanovich, K. E. (2013). Practitioner Review: Do performance-based measures and ratings of executive function assess the same construct? Journal of Child Psychology and Psychiatry, 54(2), 131-143. doi:10.1111/jcpp. 12001

Wellman, H. M., Cross, D., \& Watson, J. (2001). Meta-analysis of theory-of-mind development: The truth about false belief. Child Development, 72(3), 655-684. doi:10.1111/14678624.00304

Zelazo, P. D., \& Carlson, S. M. (2012). Hot and cool executive function in childhood and adolescence: Development and plasticity. Child Development Perspectives, 6(4), 354-360. doi:10.1111/j.1750-8606.2012.00246.x

\section{In Korean}

Ahn, J., Bang, H. J., \& Park, H. J. (2013). The relations among rapid automatized naming, executive functions, reading ability in upper grade of elementary school students. The Korean Journal of Developmental Psychology, 26(1), 85102. Retrieved from http://www.dbpia.co.kr/Article/ NODE06375282

Ahn, J. K., \& Shin, M. S. (2010). The comparison of the neuropsychological functions in subtypes of children with ADHD. Korean Journal of Psychology: General, 29(4), 959973. Retrieved from http://www.dbpia.co.kr/Article/ NODE06368178

Cha, K. (2015). Maternal interaction behaviors and the development of executive functions among Korean preschoolers. Korean Journal of Early Childhood Education, 35(2), 117-141. Retrieved from http://kiss.kstudy.com

Chi, S.-A., \& Kim, J.-E. (2016). Hot executive function of kindergartners: The affects of young children's cognitive ability, self regulation, and theory of mind. Early Childhood Education Research \& Review, 20(2), 223-247. Retrieved from http://kiss.kstudy.com

Cho, J. S., \& Lee, H. S. (2013). Comparing cognitive characteristics of children with ADHD and children with Asperger's syndrome: Focusing on intelligence and executive functions. Journal of Emotional \& Behavioral Disorders, 29(4), 39-59.

Choi, E., \& Song, H.-N. (2013). Development of children's cool and hot executive function and its relationship to children's self-regulation. Korean Journal of Child Studies, 34(5), 99114. doi:10.5723/KJCS.2013.34.5.99

Choi, Y. O. (2009). The role of information distribution and executive function in child sentence processing. The Korean Journal of Developmental Psychology, 22(4), 91109. Retrieved from http://www.dbpia.co.kr/Article/ NODE06375174

Choi, Y. O., Choi, M. H., \& Nam, M. J. (2013). Re-examination of the relationships between socioeconomic status and the development of inhibitory control among preschool Korean children. The Korean Journal of Developmental Psychology, 26(4), 107-123. Retrieved from http://www.dbpia.co.kr/ Article/NODE06375315

Chun, S.-Y. (2014). The effects of executive function impairments and covert/overt narcissism on children's peer relationships. Korean Journal of Child Psychotherapy, 9(3), 91-107. Retrieved from http://www.newnonmun.com/article=187844

Gwon, E. Y., \& Lee, H. J. (2012). Development of deception, false belief and executive function in children. The Korean Journal of Developmental Psychology, 25(2), 165184. Retrieved from http://www.dbpia.co.kr/Article/ NODE06375262

Hwang, H.-R., \& Song, H.-J. (2013). Child executive function and parenting. Journal of Rehabilitation Psychology, 20(2), 149-167. Retrieved from http://www.dbpia.co.kr/Article/ NODE02301130

Jung, C.-H., Ryu, S.-Y., \& Kim, H.-C. (2007). A comparison study of intelligence, memory and frontal-executive function in children with ADHD and normal children. Journal of the Korean Society of Biological Therapies in Psychiatry, 13(2), 307-314. Retrieved from http://www. dbpia.co.kr/Article/NODE01006346

Jung, G.-Y., Kim, W.-S., \& Rhee, K.-Y. (2014). Characteristics of executive function in sub-group of elementary school children with reading difficulties. The Journal of Special Education: Theory and Practice, 15(2), 109-125. Retrieved from http://kiss. kstudy.com

Jung, H.-Y., \& Choi, J.-W. (2014). The effects of aerobic exercise on executive function and EEG in children with attention deficit hyperactivity disorder. Korean Journal of Sport Psychology, 25(2), 13-28. doi:10.14385/KSSP.25.2.13

Kang. I.-S., \& Lee, H. (2015). Effects of exercise on executive 
functions in Korean preschool children. The Korean Journal of Developmental Psychology, 28(3), 209-226. Retrieved from http://www.koreanpsychology.or.kr

$\mathrm{Ki}$, W. (2011). A comparative study on memory span and executive function peculiarity between gifted children and normal children. Journal of Special Education for Curriculum and Instruction, 4(3), 1-18. Retrieved from http://www. newnonmun.com/article $=30342$

Kim, C.-Y., \& Lim, J.-Y. (2013). The difference of executive function by age and bilingualism among children of multicultural children and Korean children. The Korean Journal of Child Education, 22(2), 87-102. Retrieved from http://kiss.kstudy.com

Kim, H. J., \& Hong, S. O. (2011a). The relationship between intelligence and executive function of young children. Journal of Future Early Childhood Education, 18(1), 99-116. Retrieved from http://kiss.kstudy.com

Kim, H. J., \& Hong, S. O. (2011b). A comparison of executive function between gifted and non-gifted young children. The Journal of Korea Open Association for Early Childhood Education, 16(3), 259-280. Retrieved from http://kiss. kstudy.com

Kim, J. G., \& Kim, H. K. (2008). Frontal-executive functions in children with ADHD. Korean Journal of Clinical Psychology, 27(1), 139-152. Retrieved from http://www.dbpia.co.kr/ Article/NODE06371353

Kim, J. K., \& Yi, S. H. (2008). The false belief and conflicting desire task performing ability according age and executive function. Korean Journal of Early Childhood Education, 28(5), 93-113. Retrieved from http://kiss.kstudy.com

Kim, J. M., \& Kim, J. (2013). Relationship between preschoolers' executive function and verbal ability. The Korean Journal of Community Living Science, 24(3), 289-300. http://kiss. kstudy.com

Kim, J. Y., \& Baek, Y. M. (2007). The differences of memory defect and executive function in normal children and ADHD children. Korean Journal of Counseling, 8(1), 333349. Retrieved from http://kiss.kstudy.com

Kim, K. Y. \& Lee, S. E. (2007). Young children's executive function and peer interaction according to language abilities. Journal of Future Early Childhood Education, 14(1), 167-197. Retrieved from http://kiss.kstudy.com

Kim, S. Y., Chang, M. S., Seo, W. S., \& Bai, D. S. (2009). The difference of executive function in ADHD children with and without depression. Journal of the Korean Society of Biological Therapies in Psychiatry, 15(1), 21-28. Retrieved from http://www.dbpia.co.kr/Article/NODE01232340

Kim, Y. H., \& Park, S. O. (2010). The effect of group game play therapy program on the improvement of executive function in underachieved children. Journal of Emotional o
Behavioral Disorders, 26(4), 293-322.

Kim, Y. S., \& Kwak, K. J. (2014). The relation between executive function of four-year-olds and reading ability of six-yearolds: A short-term longitudinal exploration. The Korean Journal of Developmental Psychology, 27(2), 23-40. Retrieved from http://www.dbpia.co.kr/Article/NODE06375328

Kong, Y.-S., \& Lim, J.-Y. (2011). Analysis of trends in research on executive function. The Journal of Child Education, 20(1), 61-75. Retrieved from http://kiss.kstudy.com

Lee, H. J. (2011). Theory of mind and executive function in Korean children. The Korean Journal of Developmental Psychology, 24(4), 99-113. Retrieved from http://www. dbpia.co.kr/Article/NODE06375240

Lee, J. S., \& Cho, H. J. (2008). Development and the effects of group game play program experiencing as a peer-leader for children with high functioning autistic spectrum disorders. The Korean Journal of Developmental Psychology, 21(1), 113-135. Retrieved from http://www.dbpia.co.kr/Article/ NODE06375114

Lee, M. J., \& Hong, C. H. (2006). Dimensions and development of executive function. Korean Journal of Clinical Psychology, 25(2), 587-602 Retrieved from http://www.dbpia.co.kr/ Article/NODE06371254

Lee, Y.-J., Kong, Y.-S., \& Lim, J.-Y.(2014). The effects of parenting behaviors on preschoolers' executive function. Journal of Korean Home Management Association, 32(1), 13-26. Retrieved from http://www.dbpia.co.kr/Article/ NODE02374889

Lee, Y. A., \& Lee, W. J. (2015). The relationship between motor proficiency and executive function in preschoolers. Korean Journal of Child Care and Education, 11(5), 135-151. Retrieved from http://www.newnonmun.com/article=10752485

Lee, Y. M., \& Park, Y. S. (2008). The role of executive function in children's understanding of false belief. The Korean Journal of Developmental Psychology, 21(4), 57-73. Retrieved from http://www.dbpia.co.kr/Article/NODE06375136

Maeng, S. H., Jeong, Y. K., \& Kwon, M. K. (2014). Development of executive function and its relation to mathematical ability: Scale and graph understanding. The Korean Journal of Developmental Psychology, 27(1), 95-115. Retrieved from http://www.dbpia.co.kr/Article/NODE06375322

Nam, M., \& Choi, Y. (2016). Re-examination of the role of executive function in sentence processing development : inhibition versus cognitive flexibility. The Korean Journal of Developmental Psychology, 29(3), 231-251. Retrieved from http://www.dbpia.co.kr/Article/NODE07004340

No, M. \& Park, H. (2011). Influence of executive control on preschool adaption in normal and attention problem children. The Society for Cognitive Enhancement and Intervention, 2(2), 13-35. Retrieved from http://www. 
newnonmun.com/article $=53884$

Oh, S.-H., \& Ha, E.-H. (2014). The effects of children's executive function impairments and ADHD symptoms on the issue of smart phone addiction. Korean Journal of Play Therapy, 17(1), 17-35. Retrieved from http://kiss.kstudy.com

Park, E. M., \& Jung, D. Y. (2012). The effects of a meta-cognitive strategies based center-home cooperative game play program on the problematic behaviors, executive functions of children with ADHD and the maternal response of their mothers. Journal of Emotional \& Behavioral Disorders, 28(3), 487-521.

Park, H. W., \& Lee, Y. (2013). Development of executive function in 3-7 year olds: Analyses by age and maternal employment. The Korean Journal of Developmental Psychology, 26(1), 137-155. Retrieved from http://www.dbpia.co.kr/JArticle/ NODE06375285

Park, J. R., \& Song, H. J. (2012). Development and validation of children's executive function deficits inventory (CEFDI). Korean Journal of Clinical Psychology, 31(1), 1-23. Retrieved from http://www.dbpia.co.kr/Article/NODE06371592

Park, S. M., \& Shin, M. S. (2010). Comparison of executive function in children with ADHD and anxiety disorder. Journal of the Korean Academy of Child and Adolescent Psychiatry, 21(3), 147-152. Retrieved from http://www. dbpia.co.kr/Article/NODE02049873

Seo, J., \& Park, H. (2011). The effects of emotional intelligence on executive function: A comparison between normal children and attention deficit children. Journal of Cognitive Enhancement and Intervention, 2(1), 99-127. Retrieved from http://www.newnonmun.com/article $=53883$

Shin, M. S., Kim, H. M., On, S.-G., Hwang, J.-W., Kim, B.N., \& Cho, S.-C. (2006). Comparison of executive function in children with ADHD, Asperger's disorder, and learning disorder. Journal of the Korean Academy of Child and Adolescent Psychiatry, 17(2), 131-140. Retrieved from http://www.dbpia.co.kr/Article/NODE02062591

Son, H. J., \& Choi, Y. O. (2011). Relationships between preschooler's sentence processing ability and executive function. The Korean Journal of Developmental Psychology, 24(3), 87-104. Retrieved from http://www.dbpia.co.kr/ Article/NODE06375232

Song, C.-W. (2009). Executive functional characteristics of children with learning disability, children with attention deficit hyperactivity disorder, and children with normal. Journal of Special Education: Theory and Practice, 10(4), 565-590. Retrieved from http://kiss.kstudy.com

Song, C.-W., \& Byun, C.-S. (2007). Current trends of research related to executive function. Journal of Emotional \& Behavioral Disorders, 23(1), 143-162. Retrieved from http://www.dbpia.co.kr/Article/NODE06587349

Song, C.-W., Kim, H.-G., \& Chang, H.-D. (2008). Comparison of neuropsychological characteristics between the general students and the students with reading/writing Learning disabilities. The Journal of Special Children Education, 10(2), 247-266. Retrieved from http://kiss.kstudy.com

Song, M.-R., \& Ha, E.-H. (2014). The effects of children's executive function impairments and ADHD symptoms on self-directed learning capability. Korean Journal of Play Therapy, 17(2), 193-207. Retrieved from http://www.kiss. kstudy.com

Sung, K. S. \& Bang, M. Y. (2012). Comparison of the task performances in theory of mind and executive function between children with autism and MA-matched nondisabled children. The Journal of Special Children Education, 14(2), 53-71. Retrieved from http://kiss.kstudy.com

Yoo, K. S. \& Park, H. J. (2008). The relationship between children`s false belief tasks and executive functioning tasks based on theory of mind. The Journal of Child Education, 17(3), 149-159. Retrieved from http://kiss.kstudy.com

Yun, J. Y., \& Lee, H. S. (2011). A study on effects of executive function task programs on children with attention deficit hyperactivity disorder. Journal of Special Education \& Rehabilitation Science, 50(1), 143-170. Retrieved from http://www.riss.kr/link?id=A97690676

Yun, M.-H., \& Kil, K.-S. (2009). The effects of group game play program on ADHD-Liked children's executive function. Family and Environment Research, 47(4), 25-35. Retrieved from http://kiss.kstudy.com

Yun, S. M., \& Kwack, Y. S. (2015). The treatment effect of neurofeedback training on executive function in attentiondeficit hyperactivity disorder. Korean Journal of Child \& Adolescent Psychiatry, 26(1), 45-51. Retrieved from http:// www.dbpia.co.kr/Article/NODE06281526

\section{ORCID}

Jumi Lee http://orcid.org/0000-0001-5315-5266

Received October 23, 2016

Revision received March 14, 2017

Accepted March 31, 2017 